\title{
Sevilla y la carrera de Indias: las compraventas de naos (1560-1622)/
}

\author{
Seville and the Indies Run: the Purchases of Ships \\ (1560-1622)
}

\author{
Sergio M. Rodríguez Lorenzo
}

Centro de Estudios Montañeses, Santander

El negocio naviero sigue siendo uno de los aspectos menos conocidos de la carrera de Indias. En este artículo se intenta responder a la pregunta de cómo se adquieren en Sevilla los barcos que hacen la ruta trasatlántica. Para ello, se describen exhaustivamente las cláusulas de algunos contratos notariales de compraventas de naos comprendidos entre 1560 y 1622.

Palabras ClaVE: Carrera de Indias; Historia marítima; Historia naval; Sevilla; Siglo XVI; Siglo XVII

The shipping business remains one of the less known aspects of the Indies run. This article attempts to answer the question of how acquired in Seville the boats that make the transatlantic route. To this end, exhaustively describe the terms of some notarial contracts and purchases of ships between 1560 and 1622.

KeYwords: Indies run; Maritime History; Naval History; Seville; 16th Century; 17th Century 
Los barcos de la carrera de Indias podían adquirirse de varias maneras. En términos jurídicos, distinguimos dos grandes categorías: el modo originario y el modo derivativo. El modo originario más común consiste en el encargo de la construcción de una nave, aunque parece que no fue el recurso más frecuente entre los navieros asentados en Sevilla y negociantes en la carrera. ${ }^{1}$ La forma habitual de adquirir la propiedad de un buque en el puerto sevillano fue el modo derivativo mediante compraventa. A este respecto, apreciamos tres situaciones generales: aquella en la que un fabricador de origen vasco-cantábrico construye por su cuenta y riesgo una nave en los astilleros del norte peninsular para luego navegarla con mercancías hasta Sevilla o Cádiz y allí ponerla en venta; el mercado de naos de segunda mano, que manifiesta la facilidad con que las embarcaciones pueden cambiar de propietarios; y las almonedas en que las que el rey se deshace de navíos propios inhabilitados por su vejez para el servicio de armada, aunque todavía aprovechables como mercantes. ${ }^{2}$

En el presente trabajo nos hemos ocupado de las compraventas entre particulares, las más numerosas. Casi todas tienen un carácter voluntario, alguna deviene forzada por ejecución de acreedores, ${ }^{3}$ y no faltan las ventas falsas. ${ }^{4}$ Nuestra intención es responder a esta pregunta: ¿cómo solían venderse y comprarse en Sevilla las naves que surcaron la carrera de Indias? Para ello desmenuzamos las cláusulas de trescientos once contratos de compraventa de naos. La muestra — sin duda pequeña - es fruto del vaciado de 380 legajos de la sección Protocolos Notariales del Archivo Histórico Provincial de Sevilla. Ejemplos tan escasos permiten poco más que una descripción del modo en que se venden y compran las naos en el puerto hispalense; cualquier conclusión producto de un tratamiento estadístico quizá suene a exceso cientificista. El esfuerzo para obtener cosecha tan exigua se compensa, sin embargo, con la localización de otros documentos que nos servirán para conocer — a su debido tiempo — el negocio naviero de Sevilla

1 En nuestro periodo de estudio (1560-1622), únicamente hemos documentado un caso, tan excepcional como su protagonista: a principios de 1573, Juan Antonio Corzo Vicentelo entrega a Sancho de Alquiza, vecino de Fuenterrabía, la cantidad de 3.200 .000 maravedís para que construyese una nao en cualquier astillero de Guipúzcoa (Vila Vilar, 1991, 103).

2 Bastantes de estos expedientes de remates de naos se encuentran en los legajos 4872 y 4873 de la sección Contratación del Archivo General de Indias de Sevilla (en adelante AGI).

3 Archivo Histórico Provincial de Sevilla, Protocolos Notariales (en adelante AHPSPN), $7788,752 \mathrm{r}-756 \mathrm{v}$ y $826 \mathrm{r}-830 \mathrm{r}$.

4 AHPSPN, 7761, 755r-v. 
en la carrera de Indias: fletamentos de mercancías, pasajes, conciertos de maestres, pilotos y resto de la tripulación, préstamos llanos y a riesgo marítimo, compras de jarcia, bizcocho, vino, artillería, cancelaciones de deudas, ajustes de cuentas, multitud de poderes y cartas de pago. En cuanto a los límites cronológicos, 1560 y 1622 enmarcan —según Pierre Chaunu- la época de mayor esplendor de la carrera de Indias, al menos desde el punto de vista de las fuentes oficiales. ${ }^{5}$ Dos asuntos que trascienden las informaciones de los contratos de compraventa quedan para mejor ocasión: el desarrollo del mercado de adquisición de naos y el proceso de formación de precios.

\section{El contrato de compraventa}

Las formas diplomáticas del contrato notarial de compraventa de buque están condicionadas por su naturaleza jurídica. A comienzos del siglo XVII, Juan de Hevia Bolaños considera que las naves son bienes muebles sobre los que, por ejemplo, no pueden imponerse censos u otras cargas propias de los bienes raíces. ${ }^{6}$ Esta calificación proviene del derecho romano y parece indudable desde un punto de vista físico, pues el destino del buque es precisamente el traslado de un lugar a otro. Sin embargo, por sus especiales características económicas, no pareció conveniente aplicarle sin reservas las normas relativas a las cosas muebles. Esta contradicción se agudiza en la Edad Media con el ascenso del derecho germano que, a diferencia del romano, mantiene ordenamientos distintos para los bienes muebles e inmuebles. ${ }^{7}$ Se llega así a la actual consideración de la nave como una cosa mueble sui generis, que expresa su naturaleza de bien mueble al tiempo que soporta parcialmente la aplicación del régimen jurídico de los inmuebles, sobre todo en lo se refiere a la adquisición de la propiedad y a los derechos de garantía. ${ }^{8}$ Aunque desconocemos qué grado de desarrollo tuvieron estas apreciaciones en los siglos XVI y XVII, lo cierto es que las cláusulas constitutivas de los contratos de compraventa de buques se

5 Chaunu, 1959, VIII $_{2-1}, 355-840$ y VIII $_{2-2}, 851$.

6 Hevia Bolaños, 1617, lib. III, cap. II, 30.

7 González y Martínez, 1924, 10-20.

8 Broseta Pont, 1987, 760. Enríquez Rosas, 1998, 57-61. Fariña Guitián, 1955, 16. Garrigues, 1951, 514. Garrigues y Sánchez Calero, 1979, 535. Illa, 1980, 22. Jiménez Sánchez, 2000, II, 799-800. Uría, 1990, 979. 
asemejan más a las de las compraventas de casas o tierras, es decir, a las de los bienes inmuebles, que a las de otros bienes muebles como animales y utensilios diversos.

Las compraventas de naos suelen ser documentos extensos, pero no de tanta enjundia para el historiador de la carrera de Indias como de su longitud se pueda esperar. Si bien se mira, ofrecen menos riqueza de informaciones que otros títulos más breves: conciertos de tripulantes, fletamentos, operaciones de crédito, etc. La importancia del negocio justifica la redacción de amplias cláusulas que garanticen el correcto traspaso de la propiedad de unos bienes tan importantes y complejos como son los barcos. Aunque resulte engorrosa su lectura - al menos para quien no es especialista en Derecho, como es nuestro caso-, no se trata de meros requilorios jurídicos sin consecuencias. Por mucho que se repitan contrato tras contrato, no resultan indiferentes: precisan cómo se entiende la propiedad y su tradición en los siglos XVI y XVII, a qué obliga, qué derechos otorga. Al igual que cualquier otra práctica contractual, la compraventa de naos distingue los elementos personales (vendedor y comprador), reales (el buque y el precio) y formales (cláusulas de garantía).

\section{Elementos personales: vendedores y compradores}

El estudio de los señores de naos permanece en estado raquítico. Antonio Miguel Bernal, en su voluminoso trabajo sobre el crédito en la carrera de Indias, se pregunta retóricamente a quiénes pertenecieron las naves de la ruta trasatlántica y, al paso que confirma la escasez de análisis suficientes, aporta varias noticias acerca de tales figuras, en especial para la primera mitad del Quinientos. ${ }^{9}$ Ruth Pike afirma que «como norma la inversión principal de los magnates en el comercio con el Nuevo Mundo era la posesión de navíos dedicados a la Carrera de Indias», pues «el gasto del equipamiento y mantenimiento de estos barcos era tan grande que hubiera sido difícil para cualquier individuo, al menos que fuera miembro de la alta nobleza, emprenderlo en solitario». ${ }^{10}$ Que hubo nobles vinculados al negocio naviero a través de la directa posesión de buques, lo muestra la propia Pike con los casos del señor de El Viso y Santa Cruz, don Álvaro de

9 Bernal, 1993, 147-150. Algunos datos más acerca de los señores de naos en la Carrera durante el siglo XVI en Rodríguez Lorenzo, 1998, y García Bernal, 2004.

10 Pike, 1978, 41. 
Bazán el Viejo, o del duque de Arcos, don Rodrigo Ponce de León; $;{ }^{11}$ incluso la reina Juana fue propietaria de algunas naves entre los años 1507 y 1514, y otros nobles como la duquesa de Medinaceli. ${ }^{12}$ Pero no debemos pensar que el papel de la nobleza en la propiedad naval fue de semejante importancia, salvo excepciones como la de Bazán el Viejo, uno de los mayores navieros de la carrera durante la década de $1550 .{ }^{13}$ Más habitual resulta la adquisición de navíos por parte de los mercaderes. Para diversificar actividades y, sobre todo, reducir costes, algunos comerciantes se hacen con el señorío de naves, que dedican al transporte de mercancías, ya sean propias o ajenas, a cambio del flete. Probablemente el arquetipo de mercader-naviero sea - como en tantos otros aspectos- el de Juan Antonio Corzo Vicentelo, quien llega a poseer más de diez naves a lo largo de su vida. ${ }^{14}$ Varios comerciantes notables en la carrera igualmente participan en la compra de barcos: Gaspar de Arguijo, Francisco de Vivero, Antonio Jorge, Pedro Antonio Ocharte, Sancho de Quintanadueñas, Leonel de Cuadros. ${ }^{15}$ Otros colectivos representados a través de las escrituras de compraventa de buques son los corredores de lonja, sastres, clérigos o familiares de la Inquisición, aunque no siempre sea fácil asociarlos a la ruta comercial con el Nuevo Mundo. ${ }^{16}$ Pero la mayoría de los compradores y vendedores de naos son personas relacionadas directamente con la economía marítima en el Atlántico y, en particular, con la carrera de Indias. ${ }^{17}$ En realidad, los contratos de compraventas ofrecen escasos detalles sobre sus actores: nombre, vecindad o residencia y, algunas veces, la profesión. Para asociarlos al marco geográfico de la carrera debemos acudir al cruce de información con otras fuentes documentales, como poderes, operaciones de crédito, pleitos, correspondencia, fletamentos, etc.

11 Pike, 1978, 42-43.

12 Bernal, 1993, 148.

13 Mira Caballos, 2002. Martínez de Salinas Alonso, 2002. En las flotas de 1552, por ejemplo, cuatro buques son de don Álvaro de Bazán: el San Marcos y el San Lucas, con seiscientas toneladas; el San Pedro, con trescientas; y la Santa Catalina, una barca auxiliar de treinta toneladas (Chaunu, 1955, II, 482-485).

14 Vila Vilar, 1991, 105. AHPSPN, 7765, 56r-58r; AHPSPN, 7771, 671r-673v.

15 Respectivamente: Gaspar de Arguijo (Vranich, 1980, 570, 580 y 587). Francisco de Vivero (Lorenzo Sanz, 1986, I, 340; AHPSPN, 7817, 507r-509v). Antonio Jorge (AHPSPN, 16683, 419r422r). Pedro Antonio Ocharte (AHPSPN, 9236, 203r-v). Sancho de Quintanadueñas (AHPSPN, 7761, 594r-595r). Leonel de Cuadros (AHPSPN, 9304, 738r-740v).

16 AHPSPN, 12386, 668r-670v. AHPSPN, 9390, 531v-355v. AHPSPN, 12376, 72r-73r AHPSPN, 12376, 87r-88v. AHPSPN, 12382, 1197r-1198r. AHPSPN, 16853, 543r-544v.

17 «En el siglo XVI, un dueño de barco era, en muchos casos, un verdadero "hombre de mar"» (Pérez-Mallaína, 1992, 97). Rodríguez Lorenzo, 1998. 
No existe una relación directa entre la vecindad del vendedor y el lugar de procedencia del buque: el negocio naviero y la construcción naval son asuntos distintos en medios y fines. La presencia destacada de Sevilla (que aporta, por ejemplo, el 39,22\% de los vendedores), poco tiene que ver con el auténtico peso de sus astilleros, más orientados en nuestra época a labores de reparación o a levantar en sus gradas naves auxiliares de pequeño tonelaje. ${ }^{18}$ Denota más bien la importancia de la compraventa de segunda mano, así como la relativa frecuencia con que un navío puede cambiar de propietarios. Lo mismo puede decirse de los canarios $(4,79 \%)$ y andaluces de las actuales provincias de Huelva y Cádiz (respectivamente, el $0,89$ y el $2,39 \%) .{ }^{19}$ El origen cantábrico —en nuestra opinión— sí resulta significativo (un 30,50 \% entre vascongados y montañeses, con notable predominio de los primeros) y demuestra de algún modo la hegemonía de los astilleros vascos en la carrera. ${ }^{20}$ Tampoco debe sorprendernos la presencia de portugueses (cerca del $9 \%$ ). Portugal constituyó siempre una fuente importante de abastecimiento para la carrera de Indias, tanto de hombres como de unidades navales, ${ }^{21}$ hasta el punto de que las autoridades lusas llegan a prohibir la venta de sus vasos en Andalucía. ${ }^{22}$ Los procedentes de la Europa septentrional (Francia, Inglaterra, Alemania o Flandes) son todavía escasos (entre unos y otros, el 5,39 \%), lo que pone de manifiesto la suficiencia de la construcción naval de la Península o, al menos, la capacidad de abastecer sin demasiados agobios a las flotas de Indias, aunque sea a costa - o consecuencia - del abandono progresivo de otras rutas, como las mediterráneas y las del norte europeo, menos rentables o más peligrosas. Aparecen en la muestra algunos vendedores avecindados en Indias (el $3,59 \%$ ), cuyos navíos no parecen de fábrica criolla, sino que hubieran

18 Morales Padrón, 1989, 149-150. Domínguez Ortiz, 1991, 34-37, y 1986, 129-130.

19 Para algunas notas sobre la construcción naval en las islas Canarias, Lobo Cabrera, 1985. Acerca de la participación de naves onubenses en la carrera de Indias, Rodríguez Lorenzo, 2006, 38 40 .

20 Chaunu considera que al menos la mitad de las naos que navegan en la carrera de Indias entre 1560 y 1622 se han construido en astilleros vascos (Chaunu, 1959, VIII, 256-257). La estrecha vinculación entre la industria naval del País Vasco — sobre todo de Guipúzcoa, aunque de forma genérica de denominen a todas aquellas naos como «vizcaínas»— se pone de manifiesto en palabras como las siguientes, contenidas en un contrato para la fábrica de una nao en 1577: «Item, por cuanto la dicha nao ha de ser y servir para la navegación de la carrera de Indias, y el dicho maestre Juan de Calatras, vecino de la Rentería, sabe la forma y manera cómo han de ser, así dentro como fuera, para la dicha carrera...» (Barkham, 1981, 85).

21 Serrano Mangas, 1994. Rodríguez Lorenzo, 1999.

22 Costa, 1997, 150. 
SEVILLA Y LA CARRERA DE INDIAS: LAS COMPRAVENTAS DE NAOS (1560-1622)

TABLA 1

VECINDADES DE LOS VENDEDORES Y COMPRADORES DE NAOS (1560-1622)

\begin{tabular}{|c|c|c|c|c|c|}
\hline \multicolumn{3}{|c|}{ Vendedores } & \multicolumn{3}{|c|}{ Compradores } \\
\hline Origen & Casos & Porcentaje & Origen & Casos & Porcentaje \\
\hline Nacional & 277 & $84,13 \%$ & Nacional & 354 & $98,88 \%$ \\
\hline Sevilla & 131 & $39,22 \%$ & Sevilla & 308 & $86,04 \%$ \\
\hline País Vasco & 94 & $28,15 \%$ & País Vasco & 6 & $1,66 \%$ \\
\hline Canarias & 16 & $4,79 \%$ & Canarias & 11 & $3,07 \%$ \\
\hline Indias & 12 & $3,59 \%$ & Indias & 13 & $3,63 \%$ \\
\hline Cádiz & 8 & $2,39 \%$ & Cádiz & 5 & $1,4 \%$ \\
\hline Cantabria & 8 & $2,40 \%$ & Cantabria & 0 & $0 \%$ \\
\hline Huelva & 3 & $0,89 \%$ & Huelva & 7 & $1,94 \%$ \\
\hline Galicia & 3 & $0,90 \%$ & Galicia & 1 & $0,28 \%$ \\
\hline Baeza & 1 & $0,30 \%$ & Baeza & 0 & $0 \%$ \\
\hline Astorga & 1 & $0,30 \%$ & Astorga & 0 & $0 \%$ \\
\hline Toledo & 0 & $0 \%$ & Toledo & 2 & $0,56 \%$ \\
\hline Extremadura & 0 & $0 \%$ & Extremadura & 1 & $0,28 \%$ \\
\hline Cataluña & 0 & $0 \%$ & Cataluña & 1 & $0,28 \%$ \\
\hline Extranjero & 53 & $15,87 \%$ & Extranjero & 2 & $0,56 \%$ \\
\hline Portugal & 30 & $8,98 \%$ & Portugal & 2 & $0,28 \%$ \\
\hline Francia & 11 & $3,29 \%$ & Francia & 0 & $0 \%$ \\
\hline Flandes & 2 & $0,60 \%$ & Flandes & 0 & $0 \%$ \\
\hline Holanda & 4 & $1,20 \%$ & Holanda & 0 & $0 \%$ \\
\hline Inglaterra & 3 & $0,90 \%$ & Inglaterra & 0 & $0 \%$ \\
\hline Alemania & 2 & $0,60 \%$ & Alemania & 0 & $0 \%$ \\
\hline Italia & 1 & $0,30 \%$ & Italia & 0 & $0 \%$ \\
\hline Sin determinar & 4 & $1,20 \%$ & Sin determinar & 2 & $0,56 \%$ \\
\hline Total & 334 & $100 \%$ & Total & 358 & $100 \%$ \\
\hline
\end{tabular}

Fuente: Elaboración propia a partir de la documentación notarial consultada. 
aprovechado una estancia anterior en Sevilla para hacerse con una embarcación que luego explotan en la propia carrera o en el comercio regional del Caribe. ${ }^{23}$ Son vecinos de Sevilla - y entre de ellos varios de filiación vascongada (Alzate, Basterrolaza, Bengoechea, Chagoya, Echevarría, Inurriza, Laegui, Uribe, Verastegui, etc.) — quienes, por su parte, acaparan casi todas las compras de naves en una medida que no admite discusión: el $86,04 \%$ de la muestra. De vez en cuando, adquiere un navío (o parte de él) algún avecindado en Indias (3,63 \%), algún canario (3,07 \%), así como un puñado de onubenses, gaditanos y vascos aún no asentados a orillas del Guadalquivir (respectivamente el 1,94, el 1,4 y el 1,66 \%). Quizá resulte curioso que ningún extranjero -ni siquiera los naturales de Portugal, tan allegados a los castellanos $-{ }^{24}$ aproveche la estadía en Sevilla para hacerse con la propiedad de alguna de las muchísimas naves que arriban hasta el complejo portuario hispalense. ${ }^{25} \mathrm{Si}$ desde el punto de vista de la oferta el mercado sevillano de naos posee cierto carácter internacional en nuestro periodo de estudio, la demanda es claramente castellana, avecindada en Sevilla y vinculada a las necesidades de la carrera de Indias.

En la carrera de Indias predomina el naviero propietario de la totalidad del buque, aunque no faltan ejemplos de condominio en las naves. Un hecho curioso es la falta de escrituras de compañías navieras, a modo de las establecidas para el comercio o la elaboración de algún producto. ${ }^{26}$ Todo parece indicar que en el negocio naviero la mera escritura de compraventa se convierte en el documento acreditativo de la asociación por la que se reparten derechos y deberes. Desde el momento en que una persona adquiere una parte de la nave se le hace partícipe proporcional de los gastos y beneficios, sin necesidad de mayores trámites. Cuando el capitán Sebastián de Oñate compra de Domingo de Zúñiga la cuarta parte de la nao Nuestra Señora del Socorro, además de hacer frente a los 33.000 reales que le cuesta su participación en la nao, debe abonar a los otros tres copropie-

23 Sobre la actividad comercial en la cuenca del Caribe y la necesidad de navíos: Vidal Ortega, 2002, 169-208.

24 Hemos localizado esta excepción: el 1 de febrero de 1569 Antonio Távora, natural de Lisboa, vende en nombre de su padre, Francisco Matoso, la mitad del navío San Juan a los también lisboetas Manuel Enríquez y Antonio Pimentel. El barco está fletado a Manuel Caldera con destino a Santo Domingo, previa escala en Santo Tomé para cargar esclavos (AHPSPN, 12395, 638r-640v).

25 Para apreciar la magnitud de la llegada de naves extranjeras a Sevilla, Schäfer, 1934.

26 Para las compañías mercantiles, quizá la mejor introducción sea la de Martínez Gijón, 1979. Jugoso y — como siempre — muy documentado, el breve artículo de Manuel Lobo Cabrera (1993) acerca de las compañías andaluzas para el comercio canario-americano. 
tarios la cantidad de 8.280 reales en concepto de la carena y otros aprestos que ellos habían aportado a la compaña. ${ }^{27}$ La participación de varias personas en la propiedad de una nave se remonta a tiempos inmemoriales en todos los ámbitos marítimos, y la carrera de Indias no es ajena a esta práctica, aunque en ningún modo alcanza las cotas de las embarcaciones de Inglaterra u Holanda, que llegan a dividirse hasta en sesenta y cuatro partes. ${ }^{28}$ En la carrera de Indias se dividen las naos hasta en doce partes, y los propietarios rara vez pasan de cuatro, si bien parece existir una preferencia por la propiedad exclusiva de la nao o, en todo caso, compartida con otro.

\section{Elementos reales: el buque, el precio y las condiciones de pago}

Además de su carácter mobiliario sui generis, la nave puede calificarse como una cosa compuesta, agregado de partes constitutivas y pertenencias. Las partes constitutivas (casco, timón y árboles) no pueden separarse sin dejar de afectar a la existencia de la cosa misma; las pertenencias (batel, velamen, anclas, jarcias, cables y demás aparejo), aunque accesorias y dotadas de independencia, aparecen destinadas permanentemente al servicio del buque. La artillería y resto del armamento, así como las vituallas, no se consideran accesorios del buque, sino de la expedición, ni integran el concepto jurídico del barco. ${ }^{29}$ Casi todas las escrituras de compraventa hacen referencia a un inventario de bienes donde se recoge lo que en efecto se vende. Algunos de estos inventarios aparecen insertos en el tenor del contrato o en papel aparte; suelen ser bastante prolijos y constituyen un documento precioso para los especialistas en la construcción naval, pues indican la calidad y estado de conservación de muchas piezas del barco (casco, velas, árboles, antenas, cables, timón, batel), así como el material con que están fabricados o sus procedencias. La nao Santiago y San Felipe que vende Juan Bermejero en 1590 tiene cuatro cables, uno procedente de Italia, otro de Flandes y los otros dos de Calatayud; ${ }^{30}$ del navío San Antonio dice su inventario que envergó el burriquete en Cartagena de Indias, y el trinquete en La Habana. ${ }^{31}$ La nao Santa Catalina, antes

27 AHPSPN, 16845, 759r-762r.

28 Davis, 1962, 83. Israel, 1989, 21.

29 Broseta Pont, 1987, 760. Uría, 1990, 978.

30 AHPSPN, 9935, 450r-454r.

31 AHPSPN, 16762, 394v-398r. 
nombrada La Campechana, se traspasa «con sus árboles, excepto el de la mesana».32 También resultan muy útiles estos inventarios para conocer el número de piezas de artillería que incluye la venta, sin que exista una relación estable entre el tonelaje de la nave y la cantidad de cañones con que se enajena: el citado navío San Antonio, de ciento treinta toneladas, se vende con ocho piezas de artillería de hierro colado de diez a doce quintales; ${ }^{33}$ mientras que la nao La Encarnación, de trescientas toneladas, únicamente se vende con dos piezas de hierro colado de ocho y diez quintales. ${ }^{34}$

En los contratos de compraventa, las naves aparecen individualizadas por su nombre; además, se indica su tipología, el lugar de surgimiento y, casi siempre, su tonelaje. El porte se expresa por lo general en toneladas, aunque no falten ejemplos de arqueos en toneles machos. ${ }^{35}$ En casos de barcos muy pequeños también se emplean unidades como la bota o la eslora en codos como dimensión única. ${ }^{36}$ Sin embargo, el tonelaje del buque no es un dato que aparezca siempre en el tenor del documento, ni es reflejo exacto de la capacidad real del buque cuando se consigna.

El «poco más o menos» que acompaña sin falta a la declaración del porte trasluce algunos problemas ineludibles para el estudioso. Nos enfrentamos a una época que se ha dado en llamar «preestadística», donde subsiste una mentalidad que desatiende el interés por la medida precisa y se caracteriza por la diversidad local de unidades y sistemas métricos. ${ }^{37}$ Las aportaciones de Casado Soto sobre metrología naval aclararon bastante el panorama en cuanto a la definición de la tonelada y el tonel macho, así como sobre algunas de las fórmulas de arqueo utilizadas en la carrera de Indias ${ }^{38}$ pero no resuelven $-\mathrm{y}$ posiblemente nunca puedan resolverselos casos concretos de los innumerables navíos que sirvieron en esta ruta. Las informaciones procedentes de la documentación privada o notarial pueden en principio tomarse como más fiables que las derivadas de instituciones oficiales, pues el comprador de la nave está interesado en el conocimiento exacto del buque adquirido y el precio que paga por él. Sin

32 AHPSPN, 9304, 668r-670v.

33 AHPSPN, 16762, 394v-398r.

34 AHPSPN, 16837, 656r-664r.

35 AHPSPN, 12368, 708v-712v. AHPSPN, 16719, 726r-729v.

36 AHPSPN, 7800, 625v-626v (vende un barco de sesenta botas a Luis Nusio, genovés, por doscientos ducados). AHPSPN, 9290, 754v-756r (vende el barco San Diego «de diecinueve codos» a Juan de Bella, vecino de Sevilla, por trescientos reales).

37 Chaunu, 1987, 23. Kula, 1980, 135-144.

38 Casado Soto, 1988, 58-89. 
embargo, el origen heterogéneo de los vasos que acuden al mercado sevillano provoca asimismo la confluencia de distintos arqueamientos, que impiden conocer, al propio comprador y a los historiadores, si el porte declarado en el contrato de compraventa coincide con la cabida cierta del buque; tampoco el vendedor se compromete a su exactitud, y por ello no es infrecuente que a la expresión del porte le siga una fórmula que salve su responsabilidad. El palmero Simón Rodríguez vende al vecino de Sevilla Domingo de Artano las dos tercias partes de un navío de cien toneladas, «poco más o menos, y el porte y medida que fuere, sin quedar, como no quedo, obligado a satisfacción de medida». ${ }^{39}$ Lo mismo declara Lope Ochoa de Andonasgui cuando en nombre de Martín de Arano de Urquiza vende una zabra a Agustín de Paz. ${ }^{40}$ Juan Bermejero no asegura al comprador las doscientas cincuenta toneladas de su nao Santiago y San Felipe, y dispone que, en todo caso, no se descontase nada del precio si el tonelaje fuera menor ${ }^{41}$ Sin llegar a tales precauciones, aunque tampoco se coge las manos, Juan Antonio Sabariego enajena un navío de cien toneladas, «poco más o menos las que pareciere tener» ${ }^{42}$ Otros no solo dejan de consignar el arqueo, sino que venden el buque con el «porte, bondad y medida que tiene o tuviere», sin más concreción. ${ }^{43}$ Pero pocos tan conocedores de la veleidad en los arqueamientos como el capitán Agustín de Paz, quien estima un porte de trescientas toneladas para su nao Nuestra Señora de la Candelaria, «poco más o menos, las que tuviere o pareciere tener o haber tenido facultadas en las Indias». ${ }^{44}$ Por su parte, las noticias provenientes de la documentación oficial o semioficial están sujetas a sospechas por los intereses solapados que actúan sobre ella. Si el buque es objeto de un embargo o alquiler forzoso para servicio de la armada, los visitadores tienden al arqueamiento a la baja para disminuir el salario - usualmente estipulado en tantos maravedís por tonelada y mes de prestación- en beneficio del rey. Si la nave viaja como mercante, a su propietario le conviene igualmente un arqueo a la baja, pues de este modo el control fiscal recae sobre una cabida menor

39 AHPSPN, 14495, 1003v-1005v.

40 AHPSPN, 16758, 338r-341v.

41 AHPSPN, 9335, 450r-454r.

42 AHPSPN, 9287, 773-774v. Caso similar es el de Juan de Zagar Zubieta, vecino de Zumaya, que vende la mitad de su nao San Bartolomé, de «quinientas toneladas, poco más o menos, la cual os vendo por del porte que tuviere» (AHPSPN, 12476, 930r-934r).

43 AHPSPN, 12744, 592r-605r. Otros ejemplos semejantes en: AHPSPN, 16851, 1028r-1030r AHPSPN, 14494, 591-596v. AHPSPN, 14495, 1010r-1019v.

44 AHPSPN, 7942, 838r-842v. 
a la real y la diferencia, libre de gravámenes por desconocida, la rentabiliza el naviero en provecho exclusivo de su empresa. La determinación oficial del porte de un navío corre a cargo de los visitadores de naos, estrechamente vinculados al negocio naviero y cuyos sueldos salían de los bolsillos de señores y maestres por derecho de visita. No es improbable, por tanto, que en connivencia con sus pagadores aquilatasen los tonelajes por debajo de la realidad. Ante la incertidumbre en los portes de los buques, quizá la única salida para valorarlos resulte del cruce de información entre los documentos notariales y los de instituciones como la Casa de la Contratación, el Consejo de Indias o el Consulado.

Tampoco se obtienen demasiados detalles sobre el buque a través de las escrituras de compraventa. Uno importante que sí consta es el referido a la tipología. A pesar del papel intermediario del escribano en la redacción - al que le suponemos poca experiencia en calificar embarcaciones- y el uso de algunos sinónimos de la palabra «barco» a lo largo del documento — sobre todo los términos «nao»y «navío»—, existen pocos argumentos de peso que nos haga desconfiar de la tipología que se antepone al nombre de la nave en los contratos. Al fin y al cabo, el vendedor conoce perfectamente qué clase de buque traspasa y siempre está presente cuando se escritura el concierto; los compradores poseen también esa capacidad de peritaje, salvo casos contados de una parte u otra. Pero incluso dándolas por buenas, debemos reconocer nuestra ignorancia sobre el significado exacto de las tipologías declaradas, a diferencia de lo que les sucede a los protagonistas de aquellos actos mercantiles. Para un naviero del siglo XVI no es lo mismo una «nao» que un «filibote», un «patache» que una «carabela», una «urca» que un «galeón» o un «navío» que una «zabra»; sin embargo, nosotros apenas entrevemos su sentido y disertar sobre ello parece simple prurito de erudición. La mayoría de las embarcaciones se califican como «naos» $(50,48 \%)$ y «navíos» $(25,41 \%)$, de gran tradición en las navegaciones hispanas ${ }^{45}$ Ha pasado ya la época dorada de las «carabelas» (diez casos, apenas un $3,22 \%$, casi siempre de origen portugués), tan presentes en los primeros años de la carrera. Tal vez lo más llamativo sea la escasa presencia de «galeones» $(3,85 \%)$, que para la época de nuestro trabajo ya están más considerados como barcos de guerra que como mercantes y, por tanto, de poco trato entre particulares. Las compraventas de «urcas» $\mathrm{y}$ «filibotes», de origen foráneo, tampoco nos han aparecido con demasiada

45 Otte, 1996, 112-113, y 2008, 134. 
frecuencia (un 1,60 y un 3,22 \%, respectivamente); aunque sabemos que en determinados momentos su empleo en las flotas de Indias tuvo más notoriedad de lo que revelan nuestros datos, hasta el punto de que los fabricadores vascos sintieron la competencia y consiguieron del rey la prohibición de que navegasen en la carrera en $1595 .{ }^{46}$

TABLA 2

TIPOLOGÍAS DE LAS NAVES EN COMPRAVENTA (1560-1622)

\begin{tabular}{|l|r|r|}
\hline \multicolumn{1}{|c|}{ Tipología } & Casos & Porcentaje \\
\hline Nao & 157 & $50,48 \%$ \\
\hline Navío & 79 & $25,41 \%$ \\
\hline Galeón & 12 & $3,85 \%$ \\
\hline Galeaza & 2 & $0,64 \%$ \\
\hline Patache & 11 & $3,54 \%$ \\
\hline Fragata & 7 & $2,25 \%$ \\
\hline Carabela & 10 & $3,22 \%$ \\
\hline Barco & 10 & $3,22 \%$ \\
\hline Urca & 5 & $1,60 \%$ \\
\hline Filibote & 10 & $3,22 \%$ \\
\hline Zabra & 8 & $2,57 \%$ \\
\hline Total & 311 & $100 \%$ \\
\hline
\end{tabular}

Fuente: Elaboración propia a partir de la documentación notarial consultada.

Todavía más parcas son las noticias concernientes a la edad y lugar de fabricación de los buques. Con respecto a la primera, únicamente aparece alguna referencia aislada cuando se trata una nave recién construida, y así se manifiesta que la nao Nuestra Señora de las Mercedes, que vende Domingo de Larrea a Jorge Díaz, es «nueva del primer viaje»; ${ }^{47}$ o que la

46 AGI, Indiferente, 1952, lib. 4, 51r-52r. Acerca de la introducción de los filibotes en la carrera de Indias: Rodríguez Lorenzo, 2004. 
Nuestra Señora de la Concepción, traspasada por Domingo de Goizueta a Pedro de Madariaga, «es nueva de astillero». ${ }^{48}$ La novedad puede tener también un sentido relativo: Gaspar de Portu dice de su nao Los Tres Reyes que «es nueva, solo ha hecho un viaje a Terranova y este último de Guipúzcoa a este río [de Sevilla]». ${ }^{49}$ Sobre el lugar de la fábrica los datos no son mucho más abundantes. Ya sabemos que no resulta extraño el dominio de los astilleros cantábricos: Santander, Bilbao, Deusto, Portugalete, Pasajes, Deva. ${ }^{50}$ En una ocasión nos aparece una nao construida en la isla de Tenerife, ${ }^{51} \mathrm{y}$ en otro un barco de escaso porte (treinta toneladas) salido de unas gradas en San Juan del Puerto. 52

La buena y merecida fama de Clarence H. Haring extendió la opinión de que los buques que navegaron en la carrera de Indias eran los «envejecidos y destartalados» desechos de otras rutas. Esta idea, válida hasta cierto punto en 1557 — según refiere el autor a partir de una real cédula de esa fecha recogida por Encinas-,${ }^{53}$ y que otros autores prestigiosos han heredado, ${ }^{54}$ no es de aplicación general más allá de 1570 . Con el levantamiento de los Países Bajos y la amenaza pirática de los gueux de la mer, la ruta Burgos-Bilbao-Flandes comienza a ser abandonada por los barcos vizcaínos, que rápidamente son sustituidos por naves inglesas y holandesas, cuya actividad transportista no se limita a los mares del Norte y Cantábrico, sino que avanzan hasta el sur peninsular y continúan por el Mediterráneo. Desde ese momento, aunque de manera paulatina, serán los barcos de Holanda, Inglaterra y la Hansa — sin olvidarnos de las naves de Francia y la miríada

47 AHPSPN, 7787, 204r-209r.

48 AHPSPN, 9290, 990r-994r.

49 Ibidem, 925r-932r.

50 Respectivamente: AHPSPN, 12368, 708-712v. AHPSPN, 9294, 83r-85r. AHPSPN, 9350, 1062r-1063v. AHPSPN, 7787, 204r-209r. AHPSPN, 9290, 990r-994r. AGI, Contratación, 800, N. 7.

51 AHPSPN, 9320, 827r-830v.

52 AHPSPN, 16774, 663r-664r.

53 Haring, 1979, 344. El expositivo de la real cédula reza así: «Por cuanto a Nos se ha hecho relación que en la navegación de las Indias, por ser larga y trabajosa, hay necesidad de los mejores navíos que navegan por la mar, y que es al contrario lo que se usa al presente, porque de ordinario los navíos que se hacen en estos reinos, antes de que se vayan a vender a la ciudad de Sevilla navegan para Levante y otras partes, y que cuando los dueños entienden que están trabajadas y de provecho, las envían a vender a la dicha ciudad de Sevilla, y allí las compran para la carrera de las Indias; porque como en las dichas Indias por la mayor parte dan con las naos al través, no se les da nada que sean viejas...» (Encinas, 1946, lib. IV, 152-153, Real cédula a los visitadores de naos, Valladolid, 5 de mayo de 1557).

$54 \ll[. .$.$] la mayor parte de los barcos dedicados al tráfico americano fuese los más viejos de los$ puertos españoles» (Lorenzo Sanz, 1986, II, 293). «Durante el siglo estelar de la Carrera el agobio por la falta o mala calidad de los navíos llegaría a ser exasperante» (Bernal, 1999, 126). 
de carabelas portuguesas - los que acaparen la función del transporte marítimo en Europa y enlacen las tierras septentrionales con el mediodía. ${ }^{55}$ Cuando Braudel escribe «de cómo los holandeses se apoderaron de Sevilla, a partir de 1570 , sin hacer un solo disparo», ${ }^{56}$ una de las victorias menos discutidas fue la de sus navieros. Para los barcos castellanos de mediano y gran tonelaje, la única ruta marítima franca es la carrera de Indias, pues hasta la de Terranova comienza a ser apetecida por los ingleses. No extraña, por tanto, que buena parte de los vasos recién fabricados en los astilleros vascongados se dirijan hacia el emporio sevillano, lo que explica que muchos de los vendedores de naos aleguen vecindades cantábricas, en especial guipuzcoanas y vizcaínas; y aunque falten informaciones en las compraventas sobre la edad precisa de los buques, parece bastante probable que la mayoría de tales barcos navegados desde el norte sean nuevos o seminuevos: la creencia de que la carrera de Indias fue el vertedero naval de los puertos peninsulares merece ponerse en entredicho.

En ocasiones los documentos de compraventa informan de manera expresa sobre la vinculación de las naves a la carrera de Indias, bien porque declaren que han venido de ellas ${ }^{57}$ o que se aprestan con ese destino. ${ }^{58}$ Pero no siempre la embarcación en venta está inmersa en la ruta trasatlántica: del navío La Concepción, vendido en su cuarta parte al sevillano Luis de Cuenca, dice la escritura «que ha ido a la pesquería de los pargos en la Berbería»;59 de la carabela Nuestra Señora de Nazaret, «que vino cargada de bacalaos». ${ }^{60}$ A la actividad pesquera, de gran tradición en Sevilla,${ }^{61}$ se dirigen también algunos de los vasos adquiridos en el mercado hispalense.

Entre las condiciones generales declaradas en los contratos destaca la referida a la responsabilidad de los actores frente al estado de conservación de la obra viva y muerta de la nave. Por lo común, el vendedor traspasa el barco «tal cual está, sin quedar obligado a daño, adobo ni reparo alguno», pues antes de concertarse la venta el comprador lo ha visto y ha quedado satisfecho con su estado. ${ }^{62}$ Solo de vez en vez se testimonia que la nave

55 Analiza este proceso —con especial inteligencia—, Gómez-Centurión, 1988.

56 Braudel, 1993, I, 835-841.

57 AHPSPN, 9185, foliación rota. AHPSPN, 7763, 155r-157r. AHPSPN, 7776, 150r-154r. AHPSPN, 9237, 809r-812v. AHPSPN, 9304, 196r-197v. AHPSPN, 9304, 668r-670v.

58 AHPSPN, 7800, 1525r-1528r. AHPSPN, 16807, 946r-949v. AHPSPN, 16844, 917r-918r. AHPSPN, 16845, 759r-762r. AHPSPN, 9390, 351v-355v.

59 AHPSPN, 2347, 400r-401r.

60 AHPSPN, 5039, 1076r-1077v.

61 Otte, 1996, 54-56. 
tiene daño en su casco. Tomás Gallardo, por ejemplo, vende la cuarta parte de la Santa Bárbola, de quinientas toneladas, a Melchor López Palomo, señor del resto de la embarcación, y aunque la traspasa tal y como se encuentra, le advierte de que «al entrar en la barra [de Sanlúcar] tocó y quedó en seco y trae algún daño y con él se la vende». ${ }^{63}$ Incluso encontramos contratos que explicitan la causa por que el vendedor no se hace cargo de las averías en el vaso. Cuando a fines de febrero de 1611 Julián de Estrada vende a Ruy Pérez Cabrera la zabra Nuestra Señora del Rosario, dice que sus posibles daños corren por cuenta del comprador, «por estar como está dado carena, y lo ha visto y mirado el dicho Ruy Pérez Cabrera, en razón de lo cual no ha de poder alegar lesión ni engaño». ${ }^{64}$ Tampoco resulta extraño que el vendedor asegure la sanidad del buque y corra con los gastos ocasionados por las reparaciones; ${ }^{65}$ pero no de cualquier manera. Existen contratos que distinguen los desperfectos de la obra viva y los de la obra muerta. En la compraventa del galeón San Francisco, el comprador, Juan de Chagoya, se hace cargo de los daños en la obra muerta, mientras que el vendedor, Asensio de Alsola, responde por los de la obra viva. ${ }^{66}$ Lo mismo sucede con la nao San Juan Bautista de la Esperanza, de cuya obra muerta queda conforme su adquiriente, el capitán Melchor Moreno, mientras que el daño de lo cubierto por el agua se tasa en trescientos ducados, que paga Martín de Noja, apoderado del vendedor. ${ }^{67}$ En cuanto a los destrozos en la obra viva, la parte vendedora suele condicionar su responsabilidad económica a tres circunstancias: que la carena que descubra las averías se efectúe en un determinado plazo, el nombramiento de terceros que valoren tales daños, y que estos superen cierta cifra. Los plazos para dar la carena al navío son muy variables; desde los ocho días hasta los cuatro meses,

62 AHPSPN, 12379, 831r-832v. AHPSPN, 9304, 738r-739v. AHPSPN, 14493, 615r-618r. Con más detalles aparece esta cláusula en la venta de la nao Jesús, María, José que los herederos de Cristóbal de Salcedo hicieron al capitán Alonso de Cuenca: «os la vendemos de la forma y manera en que está, sin asegurársela, que no se la aseguramos, de quilla ni costado, así de lo que encubre el agua por de fuera como el lastre por de dentro, ni de las demás obras descubierta de ella» (AHPSPN, 16840, $895 \mathrm{r}-903 \mathrm{r}$ ).

63 AHPSPN, 9304, 196r-197v.

64 AHPSPN, 16811, 1018r-1019r.

65 «...asegurándosela como se la aseguro que es sana de quilla y costado, así de lo que cubre y descubre el agua por de fuera y el lastre por de dentro; y si pareciere ahora o en cualquier tiempo haber tenido o tener al presente cualquier daño en la dicha quilla y costado, lo pagaré por mi persona y bienes en cualquier cantidad que sea luego en lo que tal pareciere» (AHPSPN, 16837, 656-664r).

66 AHPSPN, 16732, 736r-740v.

67 AHPSPN, 9271, 30r-36v. 
pasando por los quince o veinte días, el mes y medio, los dos meses, los tres meses o los tres meses y medio. ${ }^{68} \mathrm{La}$ importancia de estos plazos reside en que su incumplimiento provoca que el vendedor no sufrague el coste de las reparaciones y se traspase a la cuenta del comprador. La asunción de tales gastos por parte del vendedor no significa que la carena sea responsabilidad suya; es el comprador quien tiene que concertarla con los calafates, y solo en algún caso el vendedor se obliga a poner «los oficiales y materiales que fueren necesarios». ${ }^{69}$ Valorado el daño, el procedimiento usual es que se descuente del precio de venta. ${ }^{70}$ Para la tasación de los desperfectos, cada parte del contrato tiene que nombrar un «tercero» que haga la función de árbitro; si existe discrepancia en sus peritajes, se recurre a la opinión definitiva de otro tercero que ofrezca un valor intermedio. En el concierto de compraventa de la nao La Concepción de Nuestra Señora, a fines de julio de 1561, los vendedores - Sancho de Archiniega, Toribio de la Puebla y Jerónimo de la Puebla — y el comprador — Juan Vanegas_nombran dos terceros - Juan de Bareño y Juan Sánchez, respectivamente- - pero declaran que a falta de acuerdo entre ellos, ambas partes admiten a Ginés Carrión para que decida el valor de los daños. ${ }^{71}$ Un mes más tarde, a través de un testimonio notarial, nos constan las evaluaciones de cada uno: Juan de Bareño tasa los daños en trescientos cincuenta ducados; Juan Sánchez, en cuatrocientos; y Ginés de Carrión, en trescientos setenta ducados, que es el valor que se toma como definitivo y que ha de rebajarse del precio final de venta. ${ }^{72}$ En ocasiones el vendedor toma para sí el coste de la reparación únicamente cuando su precio sobrepasa determinada suma de dinero. Existen límites modestos, como los quince ducados que estipula Francisco de Narrunda en la venta de su nao La Trinidad a Miguel de Ribas ${ }^{73}$ otros son más importantes, como los cien ducados que consignan las compraventa de la urca $E l$ Hijo Pródigo $^{74}$ y el navío portugués Nuestra

68 Respectivamente: ocho días (AHPSPN, 12384, 1040v-1042r); cuatro meses (AHPSPN, 16732, 736r-740v); quince días (AHPSPN, 12386, 668r-670v); veinte días (AHPSPN, 16840, 31r-39r); mes y medio (AHPSPN, 7764, 1276r-1279r); dos meses (AHPSPN, 9937, 623r-633v); tres meses (AHPSPN, 9312, 799r-803r); tres meses y medio (AHPSPN, 16726, 1020r-1022v).

69 AHPSPN, 7799, 497r-500v.

70 AHPSPN, 12368, 1039r-v, 1040r-v y 1041r-v. AHPSPN, 12386, 668r-670v. AHPSPN, 7760, 193r-197v. AHPSPN, 7764, 1276r-1279r. AHPSPN, 9271, 30r-36v.

71 AHPSPN, 12368, 708v-712v.

72 AHPSPN, 12638, 1042r-v.

73 AHPSPN, 7799, 705r-708r.

74 AHPSPN, 5947, 910v-914r. 
Señora de Guadalupe $;^{75}$ o los doscientos ducados de la ya citada compraventa de Sancho de Archiniega y los hermanos de la Puebla a Juan Vanegas. ${ }^{76}$ Otras veces, sin embargo, el compromiso que hace frente a las averías en el buque deja abierta las puertas a «la cantidad que sea», ${ }^{77}$ y se llegan a descontar hasta seiscientos ducados del precio del barco. ${ }^{78}$ Muy imprecisa resulta la cláusula concerniente a la sanidad del navío $L a$ Buenaventura de San Nicolás, cuyo vendedor solo se hace cargo de los daños en la obra viva si alcanzan «una cantidad considerable». ${ }^{79}$

Tras el buque, el precio que se paga por él constituye el elemento real más importante del contrato de compraventa $\mathrm{y}$, asimismo, el de análisis más complejo. Las razones por las que una nave alcanza un determinado precio son intrincadísimas. Tanto, que deducir una relación fija ducados/tonelada que dé cuenta de su progreso en el tiempo es puro cartesianismo, fantasía de historiador poco acostumbrado a los archivos. Que los costes sigan a los precios, y no viceversa, tiene su importancia en teoría económica: no discutimos ahora sobre esto ${ }^{80}$ Creemos, sin embargo, que en la conciencia del vendedor debe pesar cuánto tuvo que pagar él por la fábrica del vaso, o por su compra primitiva, para luego anunciar un precio de reventa. Con qué aparejo se vende, de qué calidad; si artillado (y con cuántas y cuáles piezas) o sin artillar. Qué edad tiene el barco, cómo se conserva, por dónde navegó. ¿Habrá sufrido alguna fortuna de mar? Cada nave es un mundo y la casuística, variada. Las condiciones del mercado, o sea, la ley de la oferta y la demanda, tienen mucho que ver en el precio. Finalmente, el problema se reduce a la negociación personal entre vendedor y comprador: el margen de beneficio que desee obtener el primero; el interés por adquirir la nave que muestre el segundo. Si hay precio $-\mathrm{y}$ los tenemos-, hubo conciliación de voluntades. Hasta donde sabemos, en la carrera de Indias las naos se compraron en completa libertad; no hubo ninguna tasa, como sí ocurrió, por ejemplo, con los fletamentos de mercancías durante algunos años. ${ }^{81}$ Otro obstáculo para la comparación es que no existen dos barcos iguales en la época de la arquitectura naval en madera y la navegación a vela. Como toda historia es de algún modo comparativa,

75 AHPSPN, 16840, 31r-39r.

76 AHPSPN, 12368, 708v-712v.

77 AHPSPN, 7764, 1276r-1279r.

78 AHPSPN, 7760, 193r-197v. AHPSPN, 9350, 1052r-1055r.

79 AHPSPN, 9937, 623r-633v.

80 Sarabia de la Calle, 1949, 53-54. Huerta de Soto, 2000, 54.

81 Rodríguez Lorenzo, 2011, 191-203. 
debemos al menos seleccionar con prudencia los términos que comparamos; en este caso, aquellas naos que parecen ser las más homogéneas: que sean nuevas, vendidas sin artillería y procedentes de una misma región. Solo obtuvimos cuatro: una de 1577, dos de 1596 y otra de 1616, todas de astilleros guipuzcoanos. La conclusión — por provisional que sea- no carece de interés: el incremento del precio por tonelada con el paso del tiempo, al menos considerado en términos corrientes; y la disminución de la ratio ducados/tonelada a partir de cierto crecimiento - que no sabríamos precisar- del tonelaje de la nave: en proporción puede llegar a salir algo más barato comprar un barco notablemente mayor que uno bastante más pequeño. La nao Nuestra Señora de las Mercedes, fabricada en Portugalete por Domingo de Larrea, arquea trescientas toneladas y se vende en 1577 a Jorge Díaz por cinco mil ochocientos ducados, con una ratio ducados/tonelada de 19,33. ${ }^{82}$ Treinta y nueve años más tarde, en 1616, la nao Nuestra Señora de la Concepción, de idéntico tonelaje, construida por Juan López de Oribar en los astilleros de Deva, se traspasa a Sebastián de Arteaga por nueve mil ducados (a treinta ducados por tonelada) ${ }^{83}$ Se ha producido un incremento de 10,67 ducados por cada tonelada. A medio camino en el tiempo, en 1596, Domingo de Goizueta vende la nao Nuestra Señora de la Concepción, cien toneladas mayor que las anteriores, por diez mil ducados, y una relación de 25 ducados/tonelada.$^{84}$ El mismo año la nao Los Tres Reyes, con seiscientas toneladas, se vende por once mil, o sea, a razón de 18,33 ducados por tonelada ${ }^{85}$ La diferencia de ratio entre la nave tonelaje más alto y la más pequeña es del 26,68 \%, favorable a Los Tres Reyes: como decíamos, en proporción una nave más grande parece salir más barata que una de tamaño menor. Si comparamos el caso de 1577 con el primero de 1596, vemos cómo una nao algo superior aumenta su precio en 5,67 ducados/tonelada en el plazo de diecinueve años, o lo que es igual: un alza del 29'33\%, proporción que veinte años más tarde (1616) alcanza un $55,19 \%$ con respecto a 1577 , y un $25,86 \%$ con relación a 1596 . Pero si comparamos la nao vendida en 1577 (de trescientas toneladas) con la de 1596 que dobla su capacidad (seiscientas toneladas), comprobamos que, en vez de aumentar, la ratio disminuye un 5,18\%.

82 AHPSPN, 7787, 204r-209r.

83 AGI, Contratación, 800, N. 7.

84 AHPSPN, 9290, 925r-932r.

85 AHPSPN, 9290, 990r-994r. 


\section{TABLA 3}

COMPARACIÓN DE PRECIOS Y RATIO DUCADOS/TONELADA DE NAOS HOMOGÉNEAS

\begin{tabular}{|c|l|l|c|c|c|}
\hline Año & \multicolumn{1}{|c|}{ Nave } & \multicolumn{1}{|c|}{ Vendedor } & Tonelaje & Precio & Ratio \\
\hline 1577 & $\begin{array}{l}\text { Ntra. Sra. de las } \\
\text { Mercedes }\end{array}$ & Domingo de Larrea & 300 & 5.800 & $19^{\prime} 33$ \\
\hline 1596 & $\begin{array}{l}\text { Ntra. Sra. de la } \\
\text { Concepción }\end{array}$ & $\begin{array}{l}\text { Domingo de } \\
\text { Goizueta }\end{array}$ & 400 & 10.000 & 25 \\
\hline 1596 & Los Tres Reyes & Gaspar de Portu & 600 & 11.000 & $18^{\prime} 33$ \\
\hline 1616 & $\begin{array}{l}\text { Ntra. Sra. de la } \\
\text { Concepción }\end{array}$ & $\begin{array}{l}\text { Juan López de } \\
\text { Oribar }\end{array}$ & 300 & 9.000 & 30 \\
\hline
\end{tabular}

Fuentes: AGI, Contratación, 800, N. 7. AHPSPN, 7787, 204r-209r. AHPSPN, 9290, 925r-932r y 990r-994r.

Es preciso reconocer lo delicado que resulta el análisis de los precios de objetos tan especiales como los barcos. El empleo de valores nominales - como hacemos nosotros - presenta el inconveniente de no dar cuenta de los efectos de la inflación en cada momento (y no es necesario desarrollar lo que ha dado de sí el debate sobre la «revolución de los precios» en los siglos XVI y XVII). Aplicar un índice deflactor es una operación aritmética sencilla y quizá tranquilice a los historiadores more geometrico, pero no resuelve el problema. Para empezar, porque los productos seleccionados en la elaboración de los índices de precios («cesta de la compra») incluyen aquellos propios del consumo ordinario - alimentos diversos, tejidos para vestir, gastos de vivienda - , pero en ningún caso bienes tan extraordinarios como las naos. Así que deflactar los precios de las naves no solo resulta de comparar lo incomparable (por ejemplo, un besugo con una zabra - tan empleadas, no obstante, para pescarlos-), sino que acaba siendo un modo de despistar al lector confiado. Que la inflación durante la segunda mitad del siglo XVI fue considerable, nadie lo pone en entredicho. Hamilton establece un índice 93,99 para los precios andaluces de 1576, y un índice 123,70 para $1596,{ }^{86}$ es decir, una subida del $29,71 \%$. Recordemos que la nao Nuestra Señora de la Concepción, de cuatrocientas toneladas, vendida por Domingo de Goizueta en 1596, incrementó su ratio ducados/tonelada

86 Hamilton, 1975, 213 
un 29,33\% con respecto a la Nuestra Señora de las Mercedes, enajenada por Domingo de Larrea en 1577. Podría decirse, entonces, que el incremento nominal del precio estuvo en consonancia con los niveles de inflación, aunque hasta que no aparezcan pruebas documentales positivas nos negamos a establecer una relación causa-efecto. Más difícil de explicar es el aumento de un $25,86 \%$ del valor de la ratio ducados/tonelada entre la nao Nuestra Señora de la Concepción, vendida por Juan López de Oribar en 1616, y la de Goizueta de 1596. Hamilton ofrece un índice 84,05 para $1616,{ }^{87}$ un $39,65 \%$ más bajo que veinte años atrás, pero con una particularidad: se trata - como toda la serie de 1601 a 1650 - de precios medidos en vellón, mientras que las naos se pagan en plata. La diferencia entre los precios abonados en uno u otro metal debía de ser escasa hacia esa fecha, pues sabemos que el premio de la plata solo alcanza el $2 \%$ en $1618 .{ }^{88}$ En todo caso, estamos en una fase de deflación y la nao de López de Oribar la han comprado por una cantidad altísima si tenemos en cuenta el nivel general de precios y su evolución desde hacía tres lustros.

No existen precios sin circunstancias, y más tienen que ver estas —en cuanto al valor monetario que alcanzan las naos - con la dinámica interna de la carrera de Indias que conforma cada coyuntura que con sofisticados índices de precios que nadie tenía en la cabeza. Si resultaba fácil o no que en 1616 una nave fuese elegida para integrar la flota; si el precio de los fletes había descendido también - como el de muchos productos-o, sin embargo, se había mantenido estable (e incluso aumentado en términos relativos); cuánta era la abundancia de tripulantes y por qué salarios estarían dispuestos a trabajar a bordo; si pretendía el señor de nao transportar mercancías propias, registradas o de contrabando; a cuánto se estaba vendiendo la pipa de vino en México o en Portobelo... Estas serían las cuestiones de verdadera importancia para quien pretendiese comprar una nao, y que nosotros — por ahora — no estamos en condiciones de dilucidar.

El precio del navío puede abonarse tanto al contado como a plazos, sin que ninguna modalidad de pago predomine sobre la otra; al tiempo, cada una de ellas se hace efectiva a través de una variada casuística que dificulta la elaboración de modelos. No resulta sencillo determinar quién de las dos partes en el contrato es la que decide finalmente las condiciones de pago. Por el lado del comprador suponemos que, además del valor de la

87 Ibidem, 229.

88 Serrano Mangas, 1996, 54. 
venta, deben conjugarse su capacidad adquisitiva, su interés por la inversión de capital propio en un corto periodo de tiempo y la seguridad que el vendedor tenga en su crédito. Por la parte vendedora, creemos que han de barajarse dos motivaciones: la necesidad más o menos imperiosa de liquidez, tanto para su subsistencia personal como para hacer frente al pago de sus deudas, y la presunción que tenga del comprador. No es esta cuestión de la confianza asunto baladí: un barco no se vende a cualquiera. El 30 de junio de 1615, Martín de Navejas escribe que ha concertado días antes la venta de su nao, pero ahora cree «será la venta nula porque el comprador no cumple con dar las seguridades que ofreció, y las haciendas raíces que tiene, aunque son muchas, entendemos tienen muchos embarazos» ${ }^{89}$ Quien desea adquirir un buque, o dispone de dinero en efectivo o tiene que ganarse la confianza del vendedor.

Cuando la compraventa estipula un precio inferior a los mil ducados el pago se efectúa al contado. No se trata de una norma impuesta, aunque sí parece práctica habitual entre los compradores..$^{90}$ Como tantos otros aspectos del mundo marítimo, la regla es la costumbre. Tampoco son extraños los pagos al contado por cuantías más onerosas, incluso pueden superar la nada despreciable cifra de los seis mil ducados, como le ocurre al sevillano Hernando de Guevara cuando adquiere de Ochoa de Capitillo la nao La Magdalena, de seiscientas siete toneladas, al precio de seis mil cuatrocientos ducados y una cadena de oro valorada en otros cincuenta, que paga a vista del escribano público. ${ }^{91}$ Supere o no la cantidad de los mil ducados, la modalidad de pago al contado distingue tres formas concretas de hacerse efectiva: la entrega de dinero en mano, el abono mediante libranza sobre tercero o la combinación de ambas. La entrega de líquido a tocateja, por lo general en el mismo momento de escrituración de la compraventa, es la opción más empleada en los pagos al contado por cuantía menor de mil ducados, y solo hemos localizado tres excepciones. ${ }^{92}$ Cuando los precios son superiores, se recurre con mayor frecuencia a los libramientos por todo el importe ${ }^{93} \mathrm{o}$ a la entrega en mano de una parte del precio y lo

89 Museo Naval de Madrid, Colección Vargas Ponce, tomo V, doc. 142, 194r.

90 Solo hemos encontrado un caso donde esta idea no se cumple: la compraventa de la nao Santa María que Juan de Uribe traspasa por 585 ducados a Diego de Armijo, quien paga al contado trescientos ducados y el resto lo aplaza en veinte meses (AHPSPN, 12384, 1040v-1042r).

91 AHPSPN, 12386, 777r-778v.

92 AHPSPN, 5497, 988r-989v. AHPSPN, 7761, 594r-595r. AHPSPN, 2339, 44v-46r.

93 AHPSPN, 7760, 193r-197v. AHPSPN, 7771, 671r-673v. AHPSPN, 7771, 1118r-1119v. AHPSPN, 9287, 773r-774v. AHPSPN, 16762, 394v-398r. 
restante transferido por libranza. ${ }^{94}$ Algunas escrituras ponen de manifiesto, sin embargo, que no todas las compraventas donde se declara un abono al contado concuerdan con la realidad. El 11 de septiembre de 1562 el carenero de Sevilla Damián Brusio compra a Diego de Molina el navío San Andrés, de ochenta toneladas, por precio de doscientos veinte ducados que dice haber pagado al contado; ${ }^{95}$ el mismo día, y en el folio siguiente del protocolo, Damián Brusio otorga una obligación de deuda a favor de Diego de Molina por los doscientos veinte ducados, «no embargante que en dicha carta de venta se decía que había recibido el dinero de contado». ${ }^{96}$ Lo mismo sucede en la venta de la mitad de la nao Santa María de los Remedios, donde su comprador, Juan Caballero, reconoce haber entregado el valor del precio al vendedor, Álvaro de Colombres, para luego desdecirse y retrasar el pago quince meses. ${ }^{97}$ Otro ejemplo más enrevesado nos informa de la falsedad de algunas de las compraventas al contado a la vez que ofrece ciertas noticias sobre las estratagemas de algunos individuos y la supuesta ingenuidad de otros. El 13 de octubre de 1618 los portugueses Francisco Viana y Manuel Viera venden a Miguel Hernández Pereira, vecino de Sevilla en el barrio de la Magdalena, la carabela Nuestra Señora de Nazaret, cuyo precio (diez mil trescientos reales) dicen recibir al contado de manos de Miguel Hernández. ${ }^{98}$ Una semana más tarde, los mismos vendedores (en esta ocasión junto al también lusitano Manuel Luis y a Martín Alfonso como fiador) aparecen vendiendo por diez mil reales la misma embarcación a Francisco de Ávila, también vecino en la Magdalena. ${ }^{99}$ Esta doble venta, ilegal, se explica en una extensa declaración contenida en el expositivo del segundo documento. Antes del 13 de octubre los vendedores y Francisco de Âvila acuerdan de palabra la venta de la carabela por los diez mil reales, a cuenta de los cuales el comprador ofrece una sortija como señal del concierto. Se interpone luego Miguel Hernández Pereira, quien persuade a Francisco Viana y a Manuel Viera - a la sazón propietarios de solo la mitad de la carabela - para que se la vendan a él, por la que ofrece trescientos reales más y la promesa de sacarlos a paz y salvo del compromiso con Francisco de Ávila. Engañados y «por no ser entendidos en

94 AHPSPN, 3428, 233v-235v. AHPSPN, 16720, 366r-368v. AHPSPN, 16843, 519r-522r. AHPSPN, 16845, 759r-762r.

95 AHPSPN, 12372, 364r-v.

96 Ibidem, 365r-v.

97 AHPSPN, 5947, 182r-v.

98 AHPSPN, 5039, 1076r-1077v.

99 AHPSPN, 5040, 250r-254r. 
negocios», ${ }^{100}$ acceden a los propósitos de Miguel Hernández y le traspasan la embarcación. Sin embargo, un hecho invalida el negocio: los vendedores declaran haber recibido en firme los diez mil trescientos reales, pero la verdad es que el comprador no les ha entregado nada y en virtud de esto dan por ninguna la venta a Miguel Hernández.

El aplazamiento de los pagos se convierte en recurso general cuando el precio de la nave excede los mil ducados. La variante más común consiste en la entrega de una parte al contado y el resto en Sevilla en una paga aplazada durante determinado tiempo, que puede oscilar entre los escasos cinco días que Juan Antonio Corzo Vicentelo demora el reembolso final de la urca Abraham $^{101}$ y los dos años consignados en el traspaso de la nao El Espíritu Santo a Juan de Uribe Apallúa. ${ }^{102}$ El plazo corriente suele ser de quince a dieciocho meses, aunque como es costumbre en Sevilla las liquidaciones de deudas se hacen coincidir con el tornaviaje de la flota que se apresta en el momento de escriturar el negocio. ${ }^{103}$ Las cantidades parciales abonadas al contado pueden igualmente entregarse a la mano ${ }^{104} \mathrm{o}$ librarse contra terceros. ${ }^{105}$ Por otra parte, las pagas aplazadas no siempre se limitan a una. A mediados de marzo de 1577, Jorge Díaz compra a Domingo de Larrea la nao Nuestra Señora de las Mercedes al precio de cinco mil ochocientos ducados, de los cuales mil se pagan al contado, dos mil a fines de marzo y el resto en un plazo máximo de veinte meses, o antes si la dicha nao volviese de cualquier viaje a las Indias; ${ }^{106}$ el 7 de diciembre de 1586, Asensio de Alsola vende al capitán Juan de Chagoya el galeón San Francisco al precio de ocho mil doscientos ducados, cuyo reembolso se fracciona en tres pagas: dos mil ducados al contado, otros mil para fines de mayo de 1587 y lo restante a fines de septiembre de 1588, con el adelanto a este plazo que suponga el regreso de la primera flota que parta desde Sanlúcar a Tierra Firme. ${ }^{107}$ Sabemos incluso de un fraccionamiento en cuatro pagas: la nao Dominguina le cuesta a Duarte de Quirós tres mil

100 Idem.

101 AHPSPN, 7765, 56r-58r.

102 AHPSPN, 7800, 1525r-1528r.

103 Véase García Fuentes, 1997.

104 AHPSPN, 7776, 150r-154r. AHPSPN, 7800, 1462r-1468r. AHPSPN, 9304, 668r-670v. AHPSPN, 16807, 946r-949v. AHPSPN, 16844, 917r-918r.

105 AHPSPN, 3406, 529v-532v. AHPSPN, 9236, 203r-v. AHPSPN, 7942, 838r-842v. AHPSPN, 12737, 560r-565v.

106 AHPSPN, 7787, 204r-209r.

107 AHPSPN, 16732, 736r-740v. 
cuatrocientos ducados; cien de ellos los había entregado como señal cuando concierta la compraventa con Martín de Achualeche, apoderado del propietario; mil quinientos se los entrega en mano ante el notario cuando se hace la escritura; otros cuatrocientos los ha de abonar en ocho días y el resto veintiún meses después. ${ }^{108}$ Otra posibilidad es demorar todo el reintegro en una, dos o tres pagas. ${ }^{109}$

\section{Elementos formales: las cláusulas de garantía}

El fraccionamiento y aplazamiento del pago de la nave supone de hecho una operación de crédito donde vendedor y comprador se transforman en acreedor y deudor respectivamente. Para proteger la satisfacción de los derechos del vendedor-acreedor, los contratos de compraventa de buques desarrollan una serie de cláusulas de garantía que reduzcan los riesgos derivados no solo del incumplimiento de las obligaciones contractuales del comprador-deudor, sino también de su posible insolvencia patrimonial o falta de recursos económicos y financieros. Dos son los principales instrumentos de garantía: el compromiso que asume un tercero frente a la deuda (fianza) o la afectación de algún bien por la cantidad adeudada (hipoteca). El recurso a la hipoteca de la nao (incluyendo sus pertenencias) aparece sin excepción en todos aquellos contratos donde se aplaza el pago de la nave. Que la nao quede hipotecada hasta completarse el abono total del precio no impide que el comprador pueda tomar posesión de ella y hacerse con su dominio. Juan de Uribe, por ejemplo, dispone en la compraventa de su nao Santa María que Diego de Armijo le entregue la primera de las dos pagas en que fracciona el precio el día que tome posesión de la nao. ${ }^{110}$ Pero algunas veces, el vendedor declara explícitamente que hasta que no se salde la deuda y la hipoteca se levante, será él quien mantenga el señorío del buque. ${ }^{111}$ En bastantes ocasiones los fletes y la artillería de la nave quedan asimismo afectados por la hipoteca. ${ }^{12}$ Raramente se hipotecan otros bienes ajenos a la empresa naviera, como por ejemplo los doscientos

108 AHPSPN, 16726, 1020r-1022v.

109 En una paga: AHPSPN, 7788, 419r-421v. AHPSPN, 16748, 338r-341v. AHPSPN, 14495, 1010r-1019v. En dos: AHPSPN, 16732, 801r-808v. Y en tres: AHPSPN, 7788, 566r-569v.

110 AHPSPN, 12384, 1040v-1042r.

111 AHPSPN, 7800, 1234r-1239v.

112 AHPSPN, 7799, 497r-500v. AHPSPN, 7799, 705r-708r. AHPSPN, 16840, 236r-243v. 
veinticinco mil maravedís de juros sobre las alcabalas de Sevilla y su partido con los que el capitán Diego Felipe de Andino garantiza el reembolso de la deuda de ocho mil ducados que le resta pagar a Bernardino de Noli por la compra de la nao San Jorge. ${ }^{113}$ Cuando la sola hipoteca no es garantía suficiente para el vendedor, se exige del comprador-deudor la presentación de fiadores llanos y abonados que se obliguen al reintegro de la deuda en caso de que su beneficiario no responda al pago. Los fiadores, a su vez, pueden comprometerse por toda la cuantía adeudada o solo por una parte de ella, remedio al que se acude cuando los pagos aplazados alcanzan sumas considerables (de seis mil a nueve mil setecientos ducados, según la muestra acopiada), repartidas sin proporción entre un número variable de personas (de tres a seis). ${ }^{114}$ Cuando los fiadores se obligan de mancomún por toda la deuda, su número nunca pasa de tres, ${ }^{115}$ y lo más normal es que se reduzca a uno; ${ }^{116}$ como es lógico, estos fiadores responden a deudas menores que las anteriormente citadas. El vendedor dispone de un último método que le garantice el cobro del precio del buque: exigir que el comprador asegure la nao de viaje y tornaviaje a las Indias por el valor de la deuda y le entregue tanto la póliza como poder cumplido para beneficiarse de ella en caso de siniestro sobre la nave. ${ }^{117}$

\section{La posesión de la nave}

En la actualidad el derecho español considera la compraventa como un contrato obligatorio no traslativo, es decir, el vendedor tiene la obligación de entregar el buque objeto del contrato al comprador, pero no transmite por sí el dominio de la nave. La propiedad del barco solo se adquiere cuando el comprador toma posesión de él, hecho que igualmente puede escriturarse ante notario. Este concepto jurídico del contrato de compraventa rige también en el derecho castellano de los siglos XVI y XVII, como explica Hevia Bolaños en su Laberinto: «Por solo la venta de la nave no se transfiere su dominio en el comprador, si no es que interviene tradición

113 AHPSPN, 16732, 801-808v.

114 AHPSPN, 16837, 656r-664r. AGI, Contratación, 800, N. 7. AHPSPN, 16851, 246r-264r. AHPSPN, 12737, 560r-565v. AHPSPN, 14494, 591r-596v.

115 AHPSPN, 9312, 799r-803r.

116 AHPSPN, 12384, 1040v-1042r. AHPSPN, 7787, 204r-209r. AHPSPN, 9937, 623r-633v. AHPSPN, 16744, 323-326r. AHPSPN, 12660, 25r-31v. AHPSPN, 7942, 838r-842v.

117 AHPSPN, 14495, 1010r-1019v. AHPSPN, 12744, 592r-605r. AHPSPN, 7465, 543r-567r. 
o posesión verdadera o fiesta de ella». ${ }^{118}$ En todos los documentos analizados se repiten las cláusulas sobre la transmisión de la propiedad del buque sin apenas diferencias. El vendedor se «desapodera» de la propiedad de la nave, permite que el comprador se sirva de ella como cosa propia y otorga poder para que tome posesión del navío. En el ínterin que esto sucede, el vendedor se obliga, como «inquilino» de la propiedad del buque, a salir en defensa de la nave ante cualquier persona que interponga pleito sobre la misma, obligación a la que ha de acudir en un plazo de tres días desde que se lo solicite el comprador. Si el vendedor incumple con este deber, el comprador puede exigirle la devolución de las cantidades pagadas por el precio del barco, tras lo cual queda sin valor la escritura de compraventa.

Las actas notariales de posesión de navíos aparecen con poca frecuencia entre los tomos de protocolos; concluimos de ello — quizá sin razónque no debe ser obligatoria la presencia del escribano público, y que en la mayoría de los casos la posesión de la nave se da por supuesta con la sola escritura de compraventa (aunque la doctrina jurídica diga lo contrario). Los navíos, junto a las tierras y las casas —es decir, las cosas inmuebles-, son los únicos bienes tras cuyas compraventas se escrituran actas de posesión. Esta tipología documental confirma por tanto la consideración del buque como cosa mueble sui generis. Aunque sencillo, el acto de posesión no está exento de cierta solemnidad. Comparecen tanto la parte vendedora como la compradora junto al notario y algunos testigos; el comprador declama alguna de las cláusulas concertadas en la escritura de compraventa y en especial aquella que le da poder para la toma de posesión. Seguidamente, el vendedor toma al comprador de la mano y lo introduce en la nave, por donde pasea y cambia cosas de lugar como muestra de su señorío. Así reza el acta de posesión de la nao La Concepción de Nuestra Señora, adquirida por Juan Vanegas, quien tras acceder a bordo de ella

se anduvo paseando por la dicha nao de una parte a la otra, y de otra a la otra, holeando la madera de la dicha nao con sus pies, en señal manifiesta, probanza y auto corporal de la dicha posesión. Y para adquisición de ello tomó de los cables y jarcia de la dicha nao y los echó de una parte a la otra, y de otra a la otra; todo esto pacíficamente, no se lo embargando ni contradiciendo persona alguna que allí estuviere. ${ }^{119}$

118 Hevia Bolaños, 1617, lib.III, cap. II, 29.

119 AHPSPN, 12368, 734v-735r. Otros ejemplos de tenor parecido en: AHPSPN, 7785, 1129v. AHPSPN, 7788, 504r-v. AHPSPN, 16733, 697v-698v. AHPSPN, 14417, 315v-318v. AHPSPN, 9295, 388r-v. 
También puede ocurrir que no comparezca el vendedor. En esta circunstancia es el escribano público quien toma de la mano al comprador y lo introduce a bordo del barco, repitiéndose el mismo ritual. ${ }^{120}$ La leyes permiten incluso que una persona desista de la posesión que haya tomado sobre un navío, como nos participa la declaración de Juan de Espinosa, vecino de Sevilla en la Magdalena, a quien le había sido rematada en Santo Domingo la carabela Nuestra Señora de Nazaret por precio de mil trescientos pesos de oro, de la que tomó posesión allí. Sin embargo, de regreso a Sevilla, declara que en realidad la carabela pertenece a su hermano, Gregorio de Espinosa, pues con sus dineros la había comprado, y que renuncia a poseerla. ${ }^{121}$

\section{A modo de conclusión}

El negocio naviero en la carrera de Indias se trata fundamentalmente de un asunto privado, entre particulares, donde las instituciones reales - $\tan$ inquisitivas en otros aspectos de la ruta - intervienen poco; y la compraventa de naos, una faceta de ese negocio que se desarrolla en libertad casi absoluta. Ni el tipo de naves objeto de las compraventas, ni sus calidades, procedencias geográficas o precios dependen de ley positiva alguna emanada de la Corona.

Diplomáticamente, los contratos de compraventa de naos se asemejan a los de compraventa de casas u otras heredades, y revelan la naturaleza jurídica de los barcos: bienes muebles sui generis, es decir, admiten parcialmente el régimen jurídico de los inmuebles, sobre todo lo relativo a adquisición de la propiedad y derechos de garantía.

La mayor parte de los señores de naos son - o han sido- hombres de mar: capitanes, maestres, pilotos. Varios cargadores a Indias también participan en la propiedad de algunas naves. Al menos entre 1560 y 1622, parece que no hubo en la carrera grandes consorcios navieros. Lo normal es que los barcos de esta ruta trasatlántica de soberanía castellana tengan un único propietario; aunque tampoco resulta extraño el condominio: dos dueños, a veces tres y casi nunca más de cuatro.

Sevilla es un mercado internacional por lo que se refiere al intercambio de mercancías, ya sea de productos primarios — «de la tierra»-

120 AHPSPN, 7759, 340v-341r

121 AHPSPN, 3427, 457r-458r. 
o manufacturas; pero no podemos decir lo mismo en cuanto a las compraventas de naos. La demanda de naves es completamente nacional, afincada en Sevilla y vinculada a la carrera de Indias. Solo en uno de los trescientos once contratos analizados aparecen compradores extranjeros. En cuanto a la oferta, el 15,87 \% son vendedores extranjeros, en buena medida portugueses. La preeminencia de sevillanos y vascos es clara (el 39,22 y el 28,15 $\%$, respectivamente), aunque parece reflejar realidades distintas y complementarias: los vecinos de Sevilla, el notable papel que tiene en la carrera de Indias la compraventa de segunda mano; los vascongados, la fertilidad de sus astilleros.

Un análisis exhaustivo de los precios de compraventa resulta intrincadísimo y hemos preferido dejarlo para otra ocasión. Como las autoridades nunca los tasaron, al menos estamos en disposición de asegurar que primó la ley de la oferta y la demanda. La calidad del buque, los costes de explotación, así como las posibilidades de beneficio, debieron de conjugarse para establecer el precio de compraventa de las naves; en definitiva, los intereses de quienes venden y compran. Pero ya solo establecer la calidad del vaso supone una tarea casi imposible. En los tiempos de la navegación a vela y la construcción en madera, cada barco es un ejemplar único. Deducir una relación ducados/tonelada que nos permita entrever la evolución de los precios, exige ciertos rasgos homogéneos de las naves comparadas. Por ejemplo: que procedan de una misma región, se vendan nuevas y sin artillería. Solo cuatro de nuestras naos cumplen estas condiciones: una de 1577, dos de 1596 y otra de 1616. En esta comparación —-sumarísima- hemos observado dos fenómenos: el incremento de la ratio ducados/tonelada con el paso del tiempo en naves de idéntico tonelaje, expresada en precios corrientes; y que proporcionalmente salga bastante más barata la ratio en buques de mayor tonelaje que en otros más pequeños.

Cuando el precio de una nao $-\mathrm{o}$ parte de ella - no supera los mil ducados, el importe siempre se abona al contado; se trata de una regla consuetudinaria, como tantas del ámbito marítimo-mercantil. Cuando debe abonarse una cantidad superior a los mil ducados, lo usual es fraccionar el pago: una parte al contado - ya sea entregada en mano, ya librada contra terceros- y otra un tiempo después, normalmente de quince a dieciocho meses, o cuando regrese la flota procedente de las Indias. Como garantía de que la deuda será pagada, se hipoteca la nave, los fletes y la artillería; si la hipoteca no se considera suficiente, se presentan fiadores; incluso se puede asegurar la nao por el valor de la deuda para que en caso de siniestro el 
acreedor pueda beneficiarse de la póliza y reducir sus pérdidas económicas. Casuística no falta, pero, en cualquier caso, no se dieron operaciones de crédito especialmente complejas. El entramado mercantil y financiero de los señores de naos en la carrera se muestra bastante más sencillo que el de los cargadores a Indias.

\section{Bibliografía}

Barkham, Michael M.: Report on $16^{\text {th }}$ Century Spanish Basque Shipbuilding, c. 1550 to c. 1600, [Otawa], Enviroment Canada (Parks Service), 1981.

Bernal, Antonio Miguel: La financiación de la Carrera de Indias (1492-1824). Dinero y crédito en el comercio colonial español con América, Madrid, Fundación El Monte, 1993.

Bernal, Antonio Miguel: «La negociación en la Carrera de Indias», en Jover Zamora, José María (dir.), Historia de España Menéndez Pidal. Tomo XVII: La formación de las sociedades iberoamericanas (1568-1700), Madrid, Espasa Calpe, 1999, 119-150.

Braudel, Fernand: El Mediterráneo y el mundo mediterráneo en la época de Felipe II, Madrid, Fondo de Cultura Económica, 1993, vol. I.

Broseta Pont, Manuel: Manual de derecho mercantil, Madrid, Tecnos, 1987.

Casado Soto, José Luis: Los barcos españoles del siglo XVI y la Gran Armada de 1588, Madrid, Editorial San Martín, 1988.

Chaunu, Hugette y Pierre: Séville et l'Atlantique. Partie stadistique. Le trafic de 1561 à 1595, París, SEVPEN, 1955, tomo II.

Chaunu, Pierre: Séville et l'Atlantique. Partie interprétative. Structures et conjuncture de l'Atlantique espagnol et hispano-américain (1504-1650), París, SEVPEN, 1959, tomos VIII y VIII $_{2-2}$.

Chaunu, Pierre: Historia cuantitativa, historia serial, México, Fondo de Cultura Económica, 1987.

Costa, Leonor Freire: Naus e Galeões na Ribeira de Lisboa. A construçaõ naval no século XVI para a Rota do Cabo, Cascais, Colibri, 1997.

Davis, Ralph: The Rise of the English Shipping Industry in the Seventeenth and Eighteenth Centuries, Londres, MacMillan \& Co. Ltd., 1962.

Domínguez Ortiz, Antonio: Historia de Sevilla. La Sevilla del siglo XVII, Sevilla, Universidad de Sevilla, 1986.

Domínguez Ortiz, Antonio: Orto y ocaso de Sevilla, Sevilla, Universidad de Sevilla, 1991. 
Encinas, Diego de: Cedulario indiano [1596], Madrid, Ediciones Cultura Hispánica, 1946.

Enríquez Rosas, David: El buque: una introducción al estudio del estatuto jurídico de las embarcaciones, México, UNAM, 1998.

Fariña Guitián, Francisco: Derecho y legislación marítima, Barcelona, Bosch, 1955.

García Bernal, Manuel Cristina: «Maestres y señores de naos en el comercio marítimo de Yucatán (Siglo XVI)», en Acosta Rodríguez, Antonio; González Rodríguez, Adolfo y Vila Vilar, Enriqueta (coords.), La Casa de la Contratación y la navegación entre España y las Indias, Sevilla, Universidad de Sevilla, CSIC y Fundación El Monte, 2004, 779-814.

García Fuentes, Lutgardo: «El crédito comercial en la Carrera de Indias (15801630)», en Entre Puebla de los Ángeles y Sevilla. Homenaje al Dr. J. A. Calderón Quijano, Sevilla, CSIC, 1997, 133-149.

Garrigues, Joaquín: Instituciones de derecho mercantil, Madrid, Imprenta Aguirre, 1951.

Garrigues, Joaquín y Sánchez Calero, Fernando: Curso de derecho mercantil, tomo II, Madrid, Imprenta Aguirre, 1979.

Gómez-Centurión Jiménez, Carlos: Felipe II, la empresa de Inglaterra y el comercio septentrional (1566-1609), Madrid, Editorial Naval, 1988.

González y Martínez, Jerónimo: Estudios de derecho hipotecario (orígenes, sistemas y fuentes), Madrid, Imprenta de Estanislao Maestre, 1924.

Hamilton, Earl J.: El tesoro americano y la revolución de los precios en España, 1501-1650, Barcelona, Editorial Ariel, 1975.

Haring, Clarence H.: Comercio y navegación entre España y las Indias en la época de los Habsburgos, México, Fondo de Cultura Económica, 1979.

Hevia Bolaños, Juan de: Labyrintho del Comercio terrestre y naval donde breve y compendiosamente trata de la Mercancía y Contratación de tierra y mar, prouechoso para Mercaderes, Negociadores, Nauegantes, y sus Consulados, Ministros de los Juyzios, profesores de Derechos, y otras personas, Lima, 1617.

Huerta de Soto, Jesús: La Escuela Austriaca. Mercado y creatividad empresarial, Madrid, Editorial Síntesis, 2000.

Illa, Raúl Eduardo: Buques: generalidades, buques nacionales, compraventa de buques, protestas de mar, Montevideo, Fundación de Cultura Universitaria, 1980.

Israel, Johnathan Irvine: Dutch Primacy in World Trade, 1585-1740, Oxford, Oxford University Press, 1989.

Jiménez Sánchez, Guillermo J. (coord.): Derecho mercantil, Barcelona, Editorial Ariel, 2000, vol. II.

Kula, Wiltold: Las medidas y los hombres, Madrid, Alianza Editorial, 1980. 
Lorenzo Sanz, Eufemio: Comercio de España con América en la época de Felipe II, Valladolid, Diputación Provincial de Valladolid, 1986, 2 vols.

Lobo Cabrera, Manuel: «Construcciones y reparaciones navales en Canarias en los siglos XVI y XVII», Anuario de Estudios Atlánticos, 31, Las Palmas de Gran Canaria, 1985, 345-374.

Lobo Cabrera, Manuel: «Compañías andaluzas en el comercio canario-americano», Historia. Instituciones. Documentos, 10, Sevilla, 1993, 197-206.

Martínez de Salinas Alonso, María Luisa: «Los negocios indianos de don Álvaro de Bazán», en Serrano Mangas, Fernando et. al. (coords.), IX Congreso Internacional de Historia de América, Badajoz, Editora Regional de Extremadura, 2002, t. I, 315-320.

Martínez Gijón, José: La compañía mercantil en Castilla hasta las ordenanzas del Consulado de Bilbao de 1737, Sevilla, Universidad de Sevilla, 1979.

Mira Caballos, Esteban: «Controversia sobre el sistema naval con América a mediados del siglo XVI: los proyectos de Álvaro de Bazán», Iberoamericana, II, 7, Berlín, 2002, 39-57.

Morales Padrón, Francisco: Historia de Sevilla. La ciudad del Quinientos, Sevilla, Universidad de Sevilla, 1989.

Otte, Enrique: Sevilla y sus mercaderes a fines de la Edad Media, Sevilla, Universidad de Sevilla y Fundación El Monte, 1996.

Otte, Enrique: Sevilla, siglo XVI: materiales para su historia económica, Sevilla, Centro de Estudios Andaluces, 2008.

Pérez-Mallaína Bueno, Pablo Emilio: Los hombres de Océano. Vida cotidiana de los tripulantes de las flotas de Indias. Siglo XVI, Sevilla, Diputación Provincial de Sevilla, 1992.

Pike, Ruth: Aristócratas y comerciantes. La sociedad sevillana del siglo XVI, Barcelona, Editorial Ariel, 1978.

Rodríguez Lorenzo, Sergio M.: «Cosme Buitrón: prestigio y fatalidad de un señor de nao en la carrera de Indias», en Armillas Vicente, José Antonio (coord.), Actas del VII Congreso Internacional de Historia de América (Zaragoza, 2-6 de julio de 1996), Zaragoza, Diputación General de Aragón, 1998, vol. III, 1797-1816.

Rodríguez Lorenzo, Sergio M.: «El Algarve y la Carrera de Indias: marginalidad provechosa de un enclave geoestratégico en el corazón del comercio con las Indias de Castilla (siglos XVI y XVII)», Revista de Historia Naval, 66, Madrid, 1999, 23-38.

Rodríguez Lorenzo, Sergio M.: «El filibote: aproximación a un cambio tecnológico naval en la carrera de Indias», Primeras Jornadas Universitarias de Arqueología Submarina y Patrimonio Sumergido. Universidad de Huelva, 18 y 19 de noviembre de 2004, Huelva [comunicación leída el 18 de noviembre; no se publicaron actas]. 
Rodríguez Lorenzo, Sergio M.: «La costa de Huelva en la Carrera de Indias (siglos XVI y XVII)», Revista de Historia Naval, 92, Madrid, 2006, 31-44.

Rodríguez Lorenzo, Sergio M.: «El fletamento de mercancías en la carrera de Indias (1560-1622): introducción a su estudio», Procesos de Mercado. Revista europea de economía política, 1, Madrid, 2011, 161-207.

Sarabia de la Calle, Luis: Instrucción de mercaderes [1544], Madrid, Joyas Bibliográficas, 1949.

Schäfer, Ernesto: «Una estadística de 1597 sobre la navegación extranjera en el puerto de Sevilla», Investigación y Progreso, 9, Madrid, 1934, 257-261.

Serrano Mangas, Fernando: La encrucijada portuguesa. Esplendor y quiebra de la unión ibérica en las Indias de Castilla, 1600-1668, Badajoz, Diputación Provincial de Badajoz, 1994.

Serrano Mangas, Fernando: Vellón y metales preciosos en la corte del rey de España (1618-1668), Madrid, Banco de España, 1996.

Uría, Rodrigo: Derecho mercantil, Madrid, Marcial Pons, 1990.

Vidal Ortega, Antonino: Cartagena de Indias y la región histórica del Caribe, 1580-1640, Sevilla, CSIC y Universidad de Sevilla, 2002.

Vila Vilar, Enriqueta: Los Corzo y los Mañara: Tipos y arquetipos del mercader con Indias, Sevilla, Escuela de Estudios Hispano-Americanos, 1991.

Vranich, S. B.: «El negociante tinerfeño Gaspar de Arguijo (1532-1594). Historia de un éxito», Anuario de Estudios Atlánticos, 26, Las Palmas de Gran Canaria, 1980, 561-612. 